\title{
Organizational and Leadership Practice of Micro Ethnic Entrepreneurship in Multicultural Context: A Structural Reproduction Analysis
}

\author{
Xiaohua Lin \\ Ryerson University \\ Jian Guan \\ Ryerson University \\ J. David Knottnerus \\ Oklahoma State University
}

One of the salient developments in North America's direct selling industry is the increasing diversity in both distributor and clientele base. It has been frequently noted that direct selling organizations comprised of certain ethnic minorities have been exceptional in terms of stability and growth in contrast to the industry's reputation for a high turnover rate. Focusing on direct selling organizations led by ethnic entrepreneurs of Chinese immigrants, the current study employs structural ritualization theory and the concept of structural reproduction and considers organizational and leadership practices that are adapted by the immigrant entrepreneurs from their culture and pre-immigration experience. Utilizing participation observation, in-depth interviews, and focus group discussions (along with document analysis), this study re-visits the time-honored issues of immigrant economic adaptation in a contemporary, multicultural context. Implications for future research, industry, and public policy based on our findings are also briefly discussed.

\section{INTRODUCTION}

This study focuses on Chinese immigrants in North America to explore the phenomena of ethnic entrepreneurship. From time-honored Chinatowns (Light 1984) to Silicon Valleys (Saxenian 1999), the Chinese have been one of most visible groups in businesses ranging from ethnic niche markets to contemporary high technology sectors. Scholars have utilized various perspectives, with the cultural explanation being arguably the most popular approach (Sanders and Nee 1996).

In regard to direct selling, recent research (Lin 2006; Lin and Guan 2005) also takes a culture-centered approach. According to these case studies, the overrepresentation and comparative success of Chinese entrepreneurs in the direct selling industry can be attributed to 
their unique cultural practices, especially those involving the strength and transference of ethnic ties in the Chinese immigrant community. In this research, the authors also mention the phenomenon of organizational reproduction whereby the Chinese direct marketers replicate the structural and leadership patterns in their motherland (Lin 2006). However, this claim was not substantiated. The current study addresses this issue. Such a study is important because the choice of direct selling as a research topic fills a void in the literature on ethnic economy. As Deakins (1999) points out, existing literature has yet to take into account the diversity of ethnic businesses.

This paper consists of five key sections. The first and second sections review background literatures on direct selling and structural ritualization theory, especially as it relates to structural reproduction and strategic ritualization. In the third section, we describe our research methodology and procedures. The findings are presented in the fourth section. Finally, the last section contains a general discussion of our findings in terms of theoretical and practical implications and directions for future studies.

\section{DIRECT SELLING INDUSTRY AND ETHNIC MINORITY PARTICIPATION}

The direct selling industry often adopts a marketing strategy which provides person-toperson services and selling to end-consumers. In contrast to fixed retail stores, companies of direct selling rely on independent distributors. The distributors purchase products wholesale from the sponsoring organizations and sell them directly to end-customers, who are typically their extended family members, friends, and acquaintances. Those distributors often sponsor other like-minded people, who like the products and business model and who in turn recruit others to expand the sales network. A distributor's compensation often includes margins on direct sales and a percentage of the sales of the entire sales group that s/he sponsors (Coughlan and Grayson 1998).

The roots of the direct selling industry can be traced back to Nutrilite Products, Inc. in the 1940s. Today, there exist about 2,000 direct selling organizations with a workforce of 30 million worldwide. Over the years, the industry has evolved from being a strictly product-driven business (personal care, nutrition, home and family care, etc.) to also being a service provider (insurance, travel, and telecommunications, etc.). In the United States, the birthplace of the industry, the direct selling industry had as of 2003 experienced nineteen consecutive years of growth in both the areas of sales and sales-force (Direct Selling Association 2004). In Canada, about $4 \%$ of the population has been involved in the direct selling business.

Due to its tradition of independence, simplicity, and minimum investment requirements, the direct selling industry provides accessible business and career opportunities to people whose market entry would otherwise be restricted by gender, age, education, or previous experience. For example, among independent distributors in Canada about $75 \%$ are women, the majority of whom do not work in a traditional occupation (only 33\% of women work full or part-time). Given its low entry barriers, the direct selling industry has become an appealing option for entrepreneurial activities (Direct Sellers Association of Canada 2003).

A newer aspect of the direct selling industry involves the dramatically increased ethnic diversity of participants. Two decades ago, the industry saw limited participation from minority populations. According to the 1998 U.S. Direct Selling Association survey, Asians represented only $1 \%$ of total participants in the direct selling industry compared to $83 \%$ for Caucasians (King and Robinson 2000). The picture is totally different today. The 2006 Performance, Potential \& 
Image Study commissioned by the Direct Sellers Association of Canada finds that $16 \%$ of direct sellers among its member companies were born outside of Canada (Mi3 Solutions 2007).

Compared to their Caucasian counterparts, minority members are more likely to become direct sellers and exhibit a great commitment to these business ventures. Once joined, they invest significantly time in the business and have a greater tendency to remain active (Lin and Hassay 2009). Concerning direct sellers from mainland China and other Chinese-speaking regions, research suggests that they have had not only a proportionally greater presence but have also achieved comparatively greater success in many of the major direct selling organizations (Lin \& Guan 2005). To explore the reasons behind this development, limited research has pointed to some unique cultural practices among Chinese direct sellers centered on their use of ethnic ties (Lin 2006). Indeed, it has been proposed that those cultures that emphasize personal relationships and encourage social obligations should be more successful in direct selling (Dyer 2001). However, questions concerning why and how such practices are created or re-created in the immigrants' new environment are largely unaddressed.

\section{STRUCTURAL RITUALIZATION THEORY}

Structural ritualization theory (Knottnerus 1997) focuses on the role rituals play in social life, especially in the formation, reproduction, and alteration of social structures. According to this perspective, rituals are a key part of everyday social life and play a crucial role in the structuring of social events regardless of cultural group membership or status and class background. They help provide symbolic meaning to human behavior, create a focus and direction to human action, and generate a sense of stability for people in social interaction. The effect of rituals is observable in more institutionalized settings and more emergent and dynamic collective contexts (Guan and Knottnerus 1999, 2006). ${ }^{1}$

Structural ritualization theory is inspired by and builds upon the seminal contributions of various scholars who have contributed to our understanding of ritual in social life (e.g. Durkheim 1965; Goffman 1967; Douglas 1970; Turner 1967; Collins 2004; Bell 1992). It does, however, present more formal definitions than many of these other perspectives and treatments of ritual. Central to the theory is the concept ritualized symbolic practice (RSP), which refers to action repertoires that are schema-driven. Schemas are cognitive frameworks. RSPs, therefore, involve regularly engaged actions that possess meaning and express symbolic themes or meanings. They help to create patterns of behavior and social relations in various social milieus. RSPs refer to the prevalent form of social behavior in which people engage in regularized and repetitious actions when interacting with others. Such social practices are found throughout social life and can include ritualized styles of interaction within different institutional settings, subcultures, and informal and formal groups. This approach emphasizes that RSPs which comprise much of the taken for granted daily lives of people rest upon cognitive schemas. While actors may not reflect upon and consciously attend to many of the behaviors that constitute their everyday lives, RSPs are still based upon cognitive structures or symbolic frameworks which express various thematic meanings.

The theory argues that four factors, salience, repetitiveness, homologousness, and RSP resources are key to the ritualization process. All four determine the rank (i.e., dominance or importance) of a RSP in a social setting.

Salience refers to the degree to which a RSP is perceived to be central to an act, action sequence, or bundle of interrelated acts in a domain or sphere of interaction. This involves the 
prominence or conspicuousness of a RSP, which can vary. Repetitiveness deals with the relative frequency with which a RSP is performed in some setting. In any particular social context the degree to which a ritualized activity occurs could range from rarely being engaged in to its being enacted extremely often. Homologousness refers to the degree of perceived similarity among different RSPs in the same or different domains of interaction. This factor refers to the fact that ritualized practices may vary in the extent to which they are similar in meaning and form. The greater the correspondence between ritualized practices, the more likely they reinforce each other. RSP resources are the human and nonhuman materials needed to engage in RSPs, which are available to actors. Resources could, for instance, range from different types of human skills and physical capacities to the kind of social ties one has with others, organizational membership, technology, and money. The greater their availability, the more likely an actor will engage in a ritualized activity.

According to the theory the greater the degree of salience of RSPs, repetitiveness of practices, presence of homologous ritualized activities, and availability of RSP resources, the greater the rank or relative standing of ritualized symbolic practices in a social setting. So, a RSP has high rank if it is repeated frequently, is quite prominent, is similar to other activities, and actors have resources to take part in it. The greater the dominance or importance (i.e., rank) of these practices, the greater the RSP's affect on actor's cognitions, behaviors, and patterned relations with others. Highly ranked RSPs can impact or influence both those who are directly engaged in these behaviors and persons who are exposed to such activities.

Another important concept from structural ritualization theory that is relevant for the present investigation is structural reproduction. According to structural ritualization theory, the greater the rank or dominance of RSPs in a social environment, the more likely new, yet similar RSPs will emerge among members of a group embedded or nested in that larger social environment. This will result in similar ritualized behaviors, relations, and social arrangements. More generally, the higher the rank in RSPs in a group the more likely such practices will endure and be repeated or reproduced among the members of these groups influencing their behaviors and relations with others (assuming the absence of countervailing influences that would interrupt or weaken these RSPs).

Finally, the theory argues that sometimes people engage in rituals that are carried out in a purposive, deliberate, and calculating manner, i.e., in a manner referred to as strategic ritualization. This concept suggest that actors may in different ways and to varying degrees strategically engage in RSPs for various purposes including self-gain and/or the pursuit of a collective goal. Stated somewhat differently, strategic ritualization refers to a situation "in which actors utilize or manipulate a system of ritualized practices in order to realize certain outcomes [that] can have profound consequences for members of society" or a particular group (Knottnerus 1997:275).

Building upon this concept, we suggest that in some situations actors may strategically choose to use certain RSPs which are already highly ranked in their social world and/or culture of origin and which are, therefore, familiar to them and comfortable to use. So, both the dominance of these RSPs in their social world and/or native culture and the strategic value of them in a particular situation contribute to their enactment and reproduction. Such ritual dynamics may occur in various social settings and can be directed towards different objectives including economic goals and the organizing of business enterprises.

These concepts and arguments can be utilized to better understand minority participation in direct selling and structural reproduction involving the ritualized behaviors and relations among 
minority group members. Some research has already cited examples such as Chinatown in arguing that culture-bound economic practices may help an ethnic group with upward mobility and status attainment (Portes and Zhou 1994). Employing structural ritualization theory, we suggest that by utilizing and, therefore, reproducing a collection of highly ranked RSPs to realize certain outcomes immigrant entrepreneurs within the direct selling industry may enhance their chances of success. In the present discussion we identify and examine such RSPs and demonstrate how Chinese entrepreneurs have strategically used these RSPs.

\section{METHODOLOGY AND RESEARCH SETTING}

To collect primary data from these case studies and to combine participant observation, documentary analysis, personal interviews, and focus group discussions, we conducted the fieldwork within a major direct selling company headquartered in the U.S. There is wide research interest in direct selling organizations but very few research projects have been implemented because of access difficulties. This is partly due to the fact that the direct selling industry is considered highly secretive in terms of information disclosure. The difficulty also lies in the fact that corporate entities involving direct selling organizations have limited power over their distributor teams and members, which means that scholars are unable to obtain effective top-down support for their research efforts.

To overcome these difficulties, our fieldwork was built around a unique participatory approach in anthropology - semiovert participant observation (Whyte 1984). Briefly, one of the researchers joined a direct selling organization (hereafter referred to as the DSO) as a functioning member, while letting fellow DSO members know of the author's dual role as an associate and researcher. This type of participant observation can generate insights into the personal experiences and activities of DSO members such as training procedures, member gatherings, and recruitment and sales processes. It has proven to be an effective way of researching direct selling business systems (Pratt 2000).

Three locations were chosen for this study including the Greater Toronto Area (GTA) and the Windsor/Essex region in Canada. The GTA is the entry point for many Chinese immigrants starting their business and has been the fastest growing market for this and other direct selling organizations. The Windsor/Essex region was chosen because it is one of the nation's most ethnically diverse regions and is a border city adjacent to the U.S. It was also chosen because the author had the opportunity to participate in the DSOs restarted up in the region (this DSO experienced a failed attempt to rebuild its network a few years ago). The other city is Miami in the U.S, where the DSO under investigation often held training sessions and conferences.

Besides participant observations, the author also conducted in-depth interviews with 42 independent distributors, the majority of whom were Chinese $(\mathrm{N}=32)$ and occupy different types of leadership roles in the DSO's networks. Among these interview participants, five of them were considered key informants who were interviewed and follow-up interviewed several times during the project. Three additional focus group discussions were organized with two comprised of Chinese Canadian participants and the other made up of mainly American Chinese participants. As a starting point, published literature was compiled and reviewed. The literature included scholarly publications, trade magazines and books, industry association publications, and government statistics as well as relevant archival information from the DSO including annual reports, policy papers, newsletters, training materials, and leadership directories. While the study focused on Chinese immigrant entrepreneurs, additional interviews and other fieldwork 
involved the ethnic groups including Caucasians, Africans, and Philippines for comparative purposes.

It has now become a legend how a small group of Chinese immigrants built up the DSO's Canadian business without deliberate corporate support in the late 1990s. Everything began when a Chinese gentleman quietly flew from California to Toronto on a regular basis. He visited relatives and friends, organized parties, and gradually built up the very first Canadian network in the DSO's name. The DSO headquarters' attention to "its" Canadian business came about only after it was caught by the surprisingly high and growing sales figures in Canada. Today, the DSO's Canadian business is largely carried out by Chinese teams and led by Chinese leaders. Chinese immigrants account for about over a half of the DSO's distributors according to the published corporate directory and about $55 \%$ of its advisory council members, who are selected based on their individual business success. Over the years, the teams have spun out beyond the Chinese immigrant communities. In most cases, new teams are created among other co-ethnics such as Philippines, Iranians, and African Canadians. Recently, Caucasian teams have also developed in Canada, both with corporate efforts and the Chinese distributor's connections. Unlike classic ethnic enclaves, a number of Chinese immigrant network marketers develop their sale teams and generate part of their sales outside of their immediate ethnic communities.

What accounts for the development of Chinese immigrants in this business venture? In exploring the causes of organizational identification and membership of groups such as this, Pratt (2000) argues for the advantages of using Amway as an extreme case. We feel that the factors contributing to the success of this particular organization are found, at least in part, within the Chinese immigrant group itself.

\section{CHINESE DIRECT SELLING ORGANIZATIONS}

Our analysis focuses on the ability of these Chinese entrepreneurs to reproduce their homegrown (i.e., culture of origin) social structures and practices. From the perspective of structural ritualization, these structures and practices can be analyzed in terms of the four criteria that determine the rank or dominance of rituals: salience, repetitiveness, homologousness, and resources.

\section{Organizational and Leadership Practices of Chinese DSOs ${ }^{2}$}

In the DSO under investigation comprised of Chinese speaking immigrants, numerous ritualized activities exist contributing to two structural features of the group: a quasi-hierarchical organization and an interdependent leader-follower relationship. In other words, individuals in this group engage in a number of RSPs which emphasize (and express symbolic themes related to) quasi-hierarchical relationships among group members and the mutual dependence of leaders and followers.

More specifically, DSO distributors work within an organizational structure wherein control is exercised without a formal hierarchy. Except for a small number of corporate staff, a direct selling firm is composed of numerous autonomous, self-managed networks. Within such networks, each direct seller is independent, self-motivated, and responsible for his or her own conduct. However, the industry's lack of formal hierarchy doesn't mean that there is no need for structure and control system. For mainstream direct selling organizations, control is accomplished through a structural system built upon a set of sanctified practices that are summarized in established corporate career manual and national training system. Established 
guidelines are conditioned in the distributors' mind through organized training, personal coaching, and management experience.

Chinese entrepreneurs, however, see this sort of operation in a very different light. Because most of the DSO businesses are home-based business, which means there no offices to go to and no supervisors looking over their shoulders, they believe a system based on voluntary compliance can hardly be effective. For that reason, they insist on a more tangible organization that at least mimics a conventional corporation. Their preference, grounded in a very different set of ritualized practices, is for what we refer to as a quasi-hierarchical organization.

For example, a major principle advocated by industry consultants is that leaders can only coach but not manage their teams. In "successful" Chinese DSO distributors, however, leaders manage their distributors. Thus, we find that Mr. Ming, a very successful DSO Chinese leader who developed a large Chinese team mostly comprised of new immigrants from mainland China, describes his philosophy as follows:

"I give orders and require reports, not yearly, monthly, or even weekly; I check on my team leaders daily and require them to do the same with their teams. People say this is a voluntary business. But to me, business is business. You either don't do it, or do it in a correct way. To me, leaders are supervisors who have to lead, and subordinates have to listen and follow. This is the only way for an organization to sustain - no exception in direct selling."

While Mr. Ming believed his approach to be similar to that of a "university," some might consider it to be that of the military. But how is it possible that such a demanding leadership style and tight discipline is accepted by Chinese DSO members? Our research has revealed an associated ritualized practice among Chinese DSO distributors, which involves a highly interdependent relationship between leaders and followers.

Here we would note that interdependency between leaders and followers (uplines and downlines) is often assumed to exist in the direct selling industry thanks to the unique types of compensation plans in the industry (Coughlan and Grayson 1998). However, there is difference between Chinese DSOs and their Caucasian counterparts. Comparatively, Chinese direct sellers are more likely to ask their leaders for help. For instance it is not unusual for leaders to evenly divide their time among the downline members in their sales teams in order to help with training and development of their skills, along with selling products and recruiting members. In contrast Caucasian sellers exhibit greater autonomy in their relationships with leaders.

For instance, one interviewee told us: "I like my senior partners to be involved in my business activities. I came from China and am not used to working totally individually - I am not comfortable with an organization that has no clear structure, no direct supervision." Another reason for the interdependent nature of relationships has to do with the competence of the Chinese direct sellers; for many Chinese immigrants direct selling has been their very first selling experience.

Reflecting the importance of the leader within this network of relationships, opening house to host business meetings is supposed to be a part of group leadership. Ms. Win was considered as a "big leader" of one Chinese team and she regularly hosts events at her home. She said in the interview: "If you're a leader, you can't expect to let the business go without contributing. You should organize the meetings at your place. When you see a new distributor wants to host meeting at his/her home, you know a new leader is on the way. You are a leader and hosting 
meeting in your home, you also feel like a leader that way." Another leader Mr. Chang then went on to state that he always prepares food at the meeting: "I want to show my appreciation for their help with this organization. Of course, I can be very critical if anyone misses the meeting."

To more formally (and precisely) analyze these ritualized practices, their importance, and the social and organizational arrangements they result in, we employ the four factors identified in structural ritualization theory which influence the rank of rituals: salience, repetitiveness, homologousness, and resources.

\section{Salience}

To begin with, the ritualized organizational and leadership practices we have just described are highly visible and prominent among Chinese DSO members. Attending a training session organized by Chinese DSO teams, a Caucasian speaker assigned by the DSO management described her experience and observations of the meeting as "shocking." In explaining why she states: "I have spoken to many groups, but never had such an experience - there is no shouting, no dancing, but quiet discipline. At the dinner table, people took turns making self-introductions. When they chatted with each other, I could tell there was such a system even though I didn't understand a word (in Chinese)." As will be discussed later, the fact that Chinese direct sellers always speak their own language has alienated non-Chinese. However, such a noticeable practice still has relatively low salience in comparison to the other quite conspicuous rituals that emphasize hierarchy and interdependence among Chinese DSO members. These practices stand in marked opposition to the official directives and regulations of the DSO industry.

To achieve standardization and consistency in its operations, DSO management emphasizes reliance on a system based on corporate-designed manuals and training materials. However, since the first group of Chinese immigrants joined its network, the company quickly discovered that Chinese direct sellers oftentimes did not conduct their business in accordance with corporate guidelines which stress, for instance, the independence of sellers and a more rational, "business like" approach. For instance, a Chinese leader will normally fulfill an order for a downline in case the latter is unable to do so for various reasons. Moreover, to "qualify" a team member, the leader will go so far as to help assign a new recruit to be a team member, an act which is not consistent with usual business practices or industry norm, but considered being an advisor to the new team member is a part of leadership practice in this case. The leader sets up example and the new members are expected to duplicate this leadership practice and help their new members in future.

Over the years, direct selling has transformed itself and moved towards a professionalism that discourages cult-like cultures and related traditions such as leader worship emphasizing instead greater formality, impersonality, and rational rule-like behavior (King and Robinson 2000). In contrast, Chinese DSO distributors have maintained part of these traditions due to deeply ingrained beliefs which emphasize the power and special status of leaders and the social, personal, and occupational needs of downline distributors. It is not unusual, for example, to hear standing crowds enthusiastically applaud leaders when they come on stage to deliver speeches or to be recognized at gatherings for Chinese DSO members.

Indeed, many trade books on direct selling warn industry practitioners against "nonprofessional" behaviors. For example, one is not supposed to stay with a fellow direct seller or a customer in their homes when visiting from out of town. This, however, could easily happen with Chinese DSO distributors. Instead of separating business from friendship or private life, as normally observed in Caucasian direct selling organizations, Chinese entrepreneurs tend to blur 
these lines by routinely adding friendship and close interpersonal ties to their business relations. Building relationship is an essential dimension in Chinese leader's mind. According to Ms. Win: "You must build relationship before you can build a business with a partner. People must like you before they like the products and business plan. I often stop by their offices or visit their stores. Only when we feel like each other, I start to introduce the products. When they have positive experience with products, I introduce the business to them. Same thing for the business partners. Don't imagine when they are your partners, you don't have to maintain the relationship. I often take them to dim sang or have coffee together."

In essence Chinese ritualized leadership styles provide guidance and direction for workers in their daily business lives and facilitate their learning how to effectively sell within the DSO system. At the same time the emphasis on interpersonal ties, friendship, and the needs of workers helps leaders build relationships with these individuals and increases their commitment to the business. Nevertheless, despite these apparent advantages conflicts can still arise between the DSO headquarter and its independent distributors. Speaking at one of the "Chinese Conventions," the corporate representative actually said: "I hate to put it like this, but the company has to make it clear - you either follow the highway that is our company's way, or else go no way." Such sentiments have not, however, discouraged the distinctive ritualized behaviors engaged in by Chinese entrepreneurs and their leaders. The prominent, central role they play in these individuals work lives attests to the salience of these social rituals within this group.

\section{Repetitiveness}

The interactions we have described between leaders and followers in the Chinese DSO are repeated frequently and on a regular basis, i.e., they are a part of their daily work lives. A main way the leaders, often referred to as "big leaders" or "small leaders," manage their teams are through formal business meetings. These meetings are held regularly based on almost set schedules. In that regard, there could be a monthly gathering for all the "small leaders" followed by weekly meetings run by each of the "small leaders" for her/his own teams. Importantly, across different levels of meetings, the quasi-hierarchical organizational structure and interdependent and personable upline-downline relationships are consistently noticeable. For example, if a meeting is held in a private residence, it must be in the leader's home. The leader normally prepares some food and the formal meeting follows the meal. And at the meeting, presentations tend to follow an order according to the members" "rank" within the organization.

The 2006 Performance, Potential \& Image Study suggests that minority direct sellers spend considerably more time in the business than other groups such as Caucasian entrepreneurs (Mi3 Solution 2007). One of the main reasons, according to the findings from our fieldwork, is that Chinese DSO distributors have a tendency to create far more collective activities than do their Caucasian counterparts. In the DSO, there are two national conventions. With the approval of the corporate management, the Chinese also hold a Chinese convention in between. Besides meetings at regional and sub-regional levels that are for everyone, Chinese teams also conduct additional meetings on their own. One reason for this, according to a Chinese leader, is that the education, language, and cultural backgrounds of many from mainland China are inadequate so that more intensive training sessions are necessary.

The most innovative programming of the Chinese DSO distributors probably involves bus trips and training cruises, where in the case of the former they build what is referred to as "bus culture." Originally, the Chinese leaders rented buses for their teams to go to conventions, largely for the sake of saving money. Immediately they realized that these closed settings could 
be effectively used as an organization building experience. Today each bus trip is associated with a relatively autonomous team and is organized by the team leader. Before the trip, the leader will design a detailed program, including activities such as performance review, experience sharing, and product training. One Chinese leader estimated that during the 24-hour period she could accomplish what would take her 24 days in a normal setting: "Actually, it's much more than that. Members get the chance to know the leaders above their immediate uplines and to build the bonds across groups."

The cruise ship training is even more intense and effective according to DSO leaders. Because of the closed environment and being away from the daily chores of family and workplace, trainees are physically and socially more concentrated and training sessions are more focused and effective. Leadership roles, team friendship and unity, and business commitment can be developed through these intense, ritualized social experiences.

\section{Homologousness}

While business meetings and formal training sessions are important mechanisms for Chinese entrepreneurs to create and develop their direct selling business, the organizational and leadership practices described above are observed in many other activities, some of which were apparently invented by this ethnic community. Importantly, all the activities mutually reinforce the maintenance of a unique culture of reciprocity and interdependency, along with clearly defined organizational patterns of leadership.

In product shows, which can be conducted at anyone's home, the sales and profits normally go to the host. However, the event is never considered an individual member's personal business, but a collective effort that will necessarily require leadership. According to one Chinese entrepreneur, the presence of the leader provides the best opportunity to show "how we are dependent upon each other." For example, while many distributors in the direct selling industry accumulate business points for commissions, the Chinese DSO leaders oftentimes give sales points to the bottom team members. By doing the leaders not only profit from the point accumulation, but their sales team members also benefit from the points that are accrued. Stated quite simply, Chinese direct sellers love home parties and clearly benefit in different ways from their participation in such collective ritual events.

Of course there are other opportunities for socializing and socialization such as picnics which serve the purpose of developing social bonds and collective identity. We have in the previous section mentioned training cruises. Over the years, the Chinese leadership team in the DSO has consistently organized cruise tours after the corporate convention. Situated in leisurely and entertaining environments, Chinese teams across the entire company (from different geographical areas) come together for business meetings and training sessions for a whole week. Different from gatherings that occur at a smaller scale, cruise tours provide unique opportunities to learn about the "best practices" among the Chinese teams while fostering social ties and feelings of reciprocity and interdependence.

\section{RSP Resources}

Ritualized behaviors are facilitated by the resources possessed by a particular group of people. In direct selling, Chinese entrepreneurs are clearly advantaged by the social capital they possess due to their being embedded in a co-ethnic group with strong social ties (Lin 2006). The business is all about networks. The strength and endurance, of ethnic networks in the Chinese community have given Chinese teams a greater level of stability and potential for expansion in 
comparison to the industry average. We have heard again and again in interviews, focus groups, and field observations that Chinese direct sellers have "recovered" personal ties lost in their immigrant experience and are able to use them in the growth of sales organizations and their customer base.

Cultural values and their representation in certain ritualized behaviors are also important resources available to Chinese direct sellers for use in their business. This is why, although Chinese leaders have often recognized the limitations of the Chinese community as a distributor and customer base, they still insist on relying on it. One Chinese leader explains: "The Chinese (community) is like iron sticks and the other communities are cement. You need cement to build up a house, but iron sticks are the very foundation that determines if you can have a solid house." According to this leader, being Chinese carries profound meaning for an organization. Essentially, certain ritualized practices and the values and symbolic themes expressed through them such as reciprocity and mutual interdependence in the Chinese tradition are simply not found in other communities.

For example, Chinese entrepreneurs tend to have a longer time horizon, which is associated with reciprocity. As one interviewee states: "We don't do inventory, but from time to time a customer suddenly emerges and you have to deliver right way. In such a case, I can always call a team member to borrow the product. This could never be a problem since I would do the same for anyone in my organization." Such a story exemplifies what Porters (1996) called social capital that embodies trust. This is why it is important to recognize that while Chinese is not only the language spoken in the Chinese selling teams, it symbolizes this type of social capital. It is a capital that is grounded, we would emphasize, in the various ritualized practices of this group that express and cultivate a sense of trust, reciprocity, and social closeness. Perhaps not surprisingly this is why we find that the internal publication of the DSO has a Chinese version that speaks to hundreds of direct sellers who otherwise would not have any connection to the organization.

\section{Rank of RSPs and Their Cultural Roots}

Our analysis of the data collected through a variety of research methods shows that RSPs involving quasi-hierarchical organizational patterns and an interdependency among leaders and followers are highly salient, repeated quite often, homologous in meaning and form, and facilitated by critically important resources. Based upon the logic of the formulation presented by structural ritualization theory these are highly ranked or dominant ritualized practices that define the daily lives of Chinese entrepreneurs working in DSOs. They influence to a significant degree their daily behaviors, relations with others, and the organizational arrangements of their group.

Such ritualized symbolic activities, we would stress, are not randomly created or developed in an ad hoc manner. Rather, findings from this research clearly indicate that the sources of the RSPs occurring among Chinese DSO distributors are derived from their homeland. They are rooted in the culture of their native country and have been reproduced in the DSOs they work in. For this reason, while bureaucratic control through a formal hierarchy is arguably the most prevailing governance approach in modern industrial organizations in countries such as Canada and the United States, we find a very different orientation among Chinese entrepreneurs. This situation is quite consistent with the conclusions of scholars who have identified an alternative approach in traditional Chinese organizations, e.g., Ouchi's (1990) study of clan culture and Redding's (1996) analysis of Chinese capitalism. 
More precisely, according to Boisot and Child (1995) the Chinese form of governance is a personalized bureaucracy whereby interpersonal relations operating through the "ranks," instead of impersonal rules and authority systems, govern the organization. Indeed, the interpersonal relations found within traditional Chinese organizations are characterized as involving interdependency. In this regard many analysts have observed so-called power distances and distinctions in China (e.g., Hofstede 1980), but what is crucial is how the hierarchical power is actually exercised (Lin 2004). What is required, we suggest, is a "below-the-surface" understanding of leadership in China which focuses on the social dynamics and more informal processes involved in organizational governance.

In sum, the extremely intensive social interaction that occurs among Chinese DSO distributors has its roots in the ritualized practices of these immigrant entrepreneurs' homeland. Such ritualized behaviors and arrangements can be profoundly important, both for Chinese immigrants in different societies such as the ones discussed here and for Chinese in their own country. For instance, Boisot and Child (1995) point out that the reason why contemporary efforts in China toward "decentralization" have not been successful is because China is a culture where information tends not to be codified. Such a situation makes the dissemination of information quite difficult. Reflecting on China's form of personalized governance, a low level of formalization they argue makes it extremely difficult, if not impossible, for effective decentralization to occur. Of course, this is exactly what we have seen among Chinese DSO distributors. As one Chinese leader put it when interviewed: "People don't like to read manuals, but are dependent on your help."

\section{DISCUSSION AND CONCLUSION}

We began this study by asking ourselves: What is the secret for the relatively successful experience of Chinese immigrants in the direct selling industry? The apparent answer is that it has to do with the nature of the industry, that is, the business is built upon personal ties and Chinese are known for close personal relationships (Lin 2006). However, we believe this is a too simplistic answer. According to the findings of this study, the performance of Chinese DSO distributors is more fully explained by concentrating on Chinese entrepreneurs' ability to replicate certain home-grown practices (i.e., ritualized behaviors) with regard to organizational structure and leadership.

This topic is especially relevant because this industry is known for its high turnover rates and inconsistent practices since there is no formalized control mechanism in the direct selling business practice. To overcome these inherent problems, corporations rely on a system built upon formal and impersonal rules and norms which are implemented through meetings, training, and written guidelines and procedures. Essentially, the industry is sustained by autonomous entrepreneurs who act freely and independently and who have ideally (from the organization's perspective) learned and follow these formal rules and guidelines.

Our findings, however, suggest that Chinese immigrants deal with the same challenges using somewhat different strategies. In the vacuum of formal control, Chinese DSO distributors through their daily ritualized practices have created a quasi-hierarchy that creates and maintains social order among members and ensures that rules (some of which are derived from their own culture) will be followed. However, the control mechanism which ensures that people follow these rules in a disciplined manner is not coercion or formal, impersonal rules (usually associated with the idea of bureaucracy) but reciprocity, i.e., leadership based on interdependency. This 
occurs through the various RSPs (including ritualized collective events) actors continually engage in which have been identified and analyzed here using concepts from structural ritualization theory.

How has this happened? Is this the result of conscious selection on Chinese entrepreneurs' part? According to our research, it is in part the result of a selection process based on trial and error. When the DSO was first introduced into the Chinese community, the business was practiced just like their Caucasian counterparts - teams were quickly built and then quickly disappeared. Soon after a group of new leaders emerged and began to engage in a "soulsearching" process as they sought to develop more effective strategies for running their businesses and selling their products. The result of this process was the reproduction of the approach used by Chinese immigrants in their homeland.

Stated in a more formal manner actors made a strategic decision, based upon their unsuccessful and successful experiences (i.e., trial and error), to engage in ritualized practices involving a certain type of leadership and governance style, quasi-hierarchical organizational arrangements, high degrees of interdependency and reciprocity between followers and leaders, and strong personal/social bonds among group members. At the same time this decision was facilitated by the strong presence of these kinds of ritualized behaviors in their country of origin. They understandably gravitated to those ritualized practices they were most familiar with and which were most meaningful and significant to them. What resulted were the highly ranked RSPs that shape the social milieu of these immigrant entrepreneurs.

This study is significant for several reasons. Previous research considered the differences between direct selling and ethnic enclaves with regard to ownership, markets, and labor forces (Lin and Guan 2005). However, the current study's focus emphasizes that minority participation in direct selling still has to be seen as part of the ethnic economy. This is consistent with the argument of Light (200x) who notes that an ethnic economy could be one that is owned by a non-ethnic group, but is conducted by co-ethnics.

Elsewhere we have also described how Chinese DSOs have to varying degrees expanded to other minority communities and even Caucasians (Lin and Guan 2005). Be that as it may, while it could be more profitable to appeal to, for instance, Caucasian clientele the Chinese DSOs tend to believe that their success is ultimately built upon a Chinese style organization. As described earlier, Chinese direct sellers use the analogy of steel vs. cement in distinguishing the role of Chinese teams vs. other ethnic teams in a DSO. A Chinese leader stated: "Without the steel, cement can't be together. That's why our focus has to be always on developing Chinese teams. It is a doable work and everyone needs to start within the (Chinese) community." So while there is some significant interaction across these organizations partly because of the nature of the products, which are not targeted at particular ethnic groups, and because no direct selling organization intends to be limited to only a particular co-ethnic market, it is still very difficult to do business across ethnic lines given the in-group tendencies among many minority populations (as seen in this study).

Key to making this happen, i.e., expanding beyond one's own group, is the emergence of a leader who is able to bridge two different co-ethnic groups. A preliminary examination of our data suggests that when this occurs such leaders can have a major impact on the success of DSOs. We suspect that when leaders are successful in this respect it is due to their possessing what has been referred to as a "biritual character" (Guan and Knottnerus 1999, 2006). A biritual character refers to actors knowing and engaging in RSPs associated with two different groups. They are 
skilled and adept at engaging in the ritualized behaviors found in both groups, such as one's own native Chinese culture and the more westernized Caucasian culture of Canada and the U.S.

Our next study will investigate this topic and assess whether some leaders are able to strategically utilize RSPs associated with both groups as they attempt to enlarge the scope of their direct selling business.

At the same time the present study and future research such as this should increase our understanding of how ritual dynamics can play such a crucial role in ethnic entrepreneurial activities contributing in some cases to the success of these enterprises.

Finally, this work has implications for industries such as DSOs and more generally how formal organizations and bureaucratic systems operate. The case of Chinese entrepreneurs shows that bureaucratic structures can take different forms and involve very different types of social relationships. Industrial and public policy which recognizes this diversity of bureaucratic systems and relations and supports these different forms would not only be a realistic response to current social conditions but a constructive and economically advantageous strategy in light of the growth of multiculturalism in many societies today.

In conclusion this study has argued that ritualized practices involving organizational and leadership practices engaged in by immigrant Chinese entrepreneurs which are derived from their native culture have contributed to the growth and stability of the economic enterprise known as direct selling organizations. Whether this will continue to be the case or whether these social dynamics may inadvertently create limitations on these organizations' potential for growth in the future is impossible to know for sure. By more clearly understanding why they have been up to this point so successful and how ritual dynamics have played a central role in their development we are, however, in a much better position to appreciate and assess future developments. This is no small achievement given the expansion of ethnic economies, immigrant and minority businesses, and multiculturalism in many societies throughout the world today.

\section{ENDNOTES}

1. For additional research utilizing the theory, see Knottnerus (1999, 2002, 2005, 2009); Knottnerus and Van de Poel-Knottnerus (1999); Van de Poel-Knottnerus and Knottnerus (2002); Sell, Knottnerus, Ellison, and Mundt (2000); Edwards and Knottnerus (2007); Knottnerus and Berry (2002); Knottnerus and LoConto (2003); Knottnerus, Monk, and Jones (1999); Knottnerus, Ulsperger, Cummins, and Osteen (2006); Minton and Knottnerus (2008); Mitra and Knottnerus (2004, 2008); Sarabia and Knottnerus (2009); Thornburg, Knottnerus, and Webb (2007, 2008); Ulsperger and Knottnerus (2007, 2008a, 2008b, 2009); Varner and Knottnerus (2002); Wu and Knottnerus (2005, 2007).

2. Conventional practice in direct selling is detailed in numerous trade books, e.g., Poe (1999); King and Robinson (2000).

\section{REFERENCES}

Bell, Catherine. (1992). Ritual Theory, Ritual Practice. Oxford: Oxford University Press.

Collins, Randall. (2004). Interaction Ritual Chains. Princeton, NJ: Princeton University Press. 
Coughlan, Anne T. and Kent Grayson. (1998). "Network Marketing Organizations:

Compensation Plans, Retail Network Growth, and Profitability." International Journal of Research in Marketing 15: 401-426.

Deakins, D. (1999). "Ethnic Minority Entrepreneurship." Pp. 80-100 in Entrepreneurship and Small Firms, $2^{\text {nd }}$ Ed., edited by A. Lindsay. Toronto: McGraw-Hill Publishing Company.

Douglas, Mary. (1970). Natural Symbols. NY: Vintage.

Durkheim, Emile. (1915) 1965. The Elementary Forms of the Religious Life. NY: Free Press.

Dyer, W. Gibb. (2001). "Network Marketing: An Effective Business Model for Family-Owned Businesses?" Family Business Review 14 (2): 97-104.

Edwards, Jennifer and J. David Knottnerus. (2007). "The Orange Order: Strategic Ritualization and Its Organizational Antecedents." International Journal of Contemporary Sociology 44:179199.

. Forthcoming. "The Orange Order: Parades, Other Rituals, and Their Outcomes."

Sociological Focus.

Goffman, Erving. (1967). Interaction Ritual: Essays on Face-To-Face Behavior. Garden City, NY: Anchor Books.

Guan, Jian and J. David Knottnerus. (1999). "A Structural Ritualization Analysis of the Process of Acculturation and Marginalization of Chinese Americans." Humboldt Journal of Social Relations 25:43-95.

. (2006). "Chinatown Under Siege: Community Protest and Structural Ritualization Theory." Humboldt Journal of Social Relations 30:5-52.

King, Charles W. and James W. Robinson. (2000). The New Professionals: The Rise of Network Marketing as the Next Major Profession. New York: Three Rivers Press.

Knottnerus, J. David. (1997). "The Theory of Structural Ritualization." Pp. 257-279 in Advances in Group Processes, Volume 14, edited by Barry Markovsky, Michael J. Lovaglia and Lisa Troyer. Greenwich, CT: JAI Press.

. (1999). "Status Structures and Ritualized Relations in the Slave Plantation System. Pp. 137-147 in Plantation Society and Race Relations: The Origins of Inequality, edited by Thomas J. Durant, Jr. and J. David Knottnerus. Westport, CT: Praeger.

. (2002). "Agency, Structure and Deritualization: A Comparative Investigation of Extreme Disruptions of Social Order." Pp. 85-106 in Structure, Culture and History: Recent Issues in Social Theory, edited by Sing C. Chew and J. David Knottnerus. Lanham, MD: Rowman \& Littlefield. 
. (2005). "The Need for Theory and the Value of Cooperation: Disruption and Deritualization." (Presidential Address, Mid-South Sociological Association, Baton Rouge, 2003). Sociological Spectrum 25:5-19.

. (2009). "Structural Ritualization Theory: Application and Change" Pp. 70-84 in Bureaucratic Culture and Escalating World Problems: Advancing the Sociological Imagination, edited by J. David Knottnerus and Bernard Phillips. Boulder, CO: Paradigm Publishers.

. Forthcoming. Ritual as a Missing Link within Sociology: Structural Ritualization Theory and Research. Boulder, CO: Paradigm Publishers.

Knottnerus, J. David and Phyllis E. Berry. (2002). "Spartan Society: Structural Ritualization in an Ancient Social System." Humboldt Journal of Social Relations 27:1-42.

Knottnerus, J. David and David G. LoConto. (2003). "Strategic Ritualization and Ethnicity: A Typology and Analysis of Ritual Enactments in an Italian American Community." Sociological Spectrum 23:425-461.

Knottnerus, J. David, David L. Monk, and Edward Jones. (1999). "The Slave Plantation System from a Total Institution Perspective." Pp. 17-27 In Plantation Society and Race Relations: The Origins of Inequality, edited by Thomas J. Durant, Jr. and J. David Knottnerus. Westport, CT: Praeger.

Knottnerus, J. David, Jason S. Ulsperger, Summer Cummins, and Elaina Osteen. (2006). "Exposing Enron: Media Representations of Ritualized Deviance in Corporate Culture." Crime, Media, Culture: An International Journal 2:177-195.

Knottnerus, J. David and Frederique Van de Poel-Knottnerus. (1999). The Social Worlds of Male and Female Children in the Nineteenth Century French Educational System: Youth, Rituals and Elites. Lewiston, NY: Edwin Mellen Press.

Lin, Xiaohua and Derek Hassay. (2009). "Minority Participation in Direct Selling: Necessity versus Opportunity-Driven Microentrepreneurship." Under review with Small \& Mid-Sized Enterprises and Entrepreneurship Review.

Lin, Xiaohua. (2007). Chinese Entrepreneurs in Network Marketing Organizations: A CultureModerated Social Capital Perspective. Journal of Small Business and Entrepreneurship 20 (3): 273-288.

Lin, Xiaohua and Jian Guan. (2006). "Immigration Participation in Network Marketing Organizations: Acculturation and Identification." Pp. 428-446 in Multicultural Days: An International Perspective, edited by Dawn Zinga. Newcastle, UK: Cambridge Scholars Press.

Minton, Carol and J. David Knottnerus. (2008). "Ritualized Duties: The Social Construction of Gender Inequality in Malawi.” International Review of Modern Sociology 34:181-210. 
Mitra, Aditi and J. David Knottnerus. (2004). "Royal Women in Ancient India: The Ritualization of Inequality in a Patriarchal Social Order." International Journal of Contemporary Sociology 41:215-231.

. (2008). "Sacrificing Women: A Study of Ritualized Practices Among Women Volunteers in India." Voluntas: International Journal of Voluntary and Nonprofit Organizations 19:242267.

Poe, Richard. (1999). Wave 4: Network Marketing in the $21^{\text {st }}$ Century. New York: Three Rivers Press.

Sarabia, Daniel and J. David Knottnerus. (2009). "Ecological Stress and Deritualization in East Asia: Ritual Practices during Dark Age Phases.” International Journal of Sociology and Anthropology (Open Access Online Journal): 1(1):012-025, May. www.academicjournals.org/IJSA/contents/2009cont/May.htm

Sanders, J. M. and Nee, V. (1996). "Immigrant Self-Employment: The Family as Social Capital and the Value of Human Capital." American Sociological Review 61 (2): 230-249.

Sell, Jane, J. David Knottnerus, Christopher Ellison, and Heather Mundt. (2000). "Reproducing Social Structure in Task Groups: The Role of Structural Ritualization." Social Forces 79:453475.

Thornburg, P. Alex, J. David Knottnerus, and Gary R. Webb. (2007). "Disaster and Deritualization: A Re-interpretation of Findings from Early Disaster Research." The Social Science Journal 44:161-166.

. (2008). "Ritual and Disruption: Insights from Early Disaster Research." International Journal of Sociological Research 1:91-109.

Turner, Victor. (1967). The Forest of Symbols: Aspects of Ndembu Ritual. Ithaca, NY: Cornell University Press.

Ulsperger, Jason S. and J. David Knottnerus. (2007). "Long-term Care Workers and Bureaucracy: The Occupational Ritualization of Maltreatment in Nursing Homes and Recommended Policies." Journal of Applied Social Science 1:52-70.

. (2008) a. "Enron: Organizational Rituals as Deviance." Pp. 311-314 in Readings in Deviant Behavior, $5^{\text {th }}$ ed., edited by Alex Thio, Thomas C. Calhoun, and Addrain Conyers. Boston: Allyn and Bacon.

. (2008) b. "The Social Dynamics of Elder Care: Rituals of Bureaucracy and Physical Neglect in Nursing Homes." Sociological Spectrum 28:357-388. 
. (2009). "Institutionalized Elder Abuse: Bureaucratic Ritualization and Transformation of Physical Neglect in Nursing Homes" Pp. 134-155 in Bureaucratic Culture and Escalating World Problems: Advancing the Sociological Imagination, edited by J. David Knottnerus and Bernard Phillips. Boulder, CO: Paradigm Publishers.

. Forthcoming. "Illusions of Affection: Bureaucracy and Emotional Neglect in Nursing Homes." Humanity and Society.

Van de Poel-Knottnerus, Frederique and J. David Knottnerus. (2002). Literary Narratives on the Nineteenth and Early Twentieth-Century French Elite Educational System: Rituals and Total Institutions. Lewiston, NY: Edwin Mellen Press.

Varner, Monica K. and J. David Knottnerus. (2002). "Civility, Rituals and Exclusion: The Emergence of American Golf During the Late Nineteenth and Early Twentieth Centuries." Sociological Inquiry 72:426-441.

Wu, Yanhong and J. David Knottnerus. (2005). "Ritualized Daily Practices: A Study of Chinese 'Educated Youth."' Shehui (Society) (6):167-185.

. (2007). "The Origins of Ritualized Daily Practices: From Lei Feng's Diary to Educated Youth's Diaries.” Shehui (Society) (1):98-119. 